estudios del habitat FAU:me=
Estudios del Hábitat

ISSN: 2422-6483

aefau@fau.unlp.edu.ar

Universidad Nacional de La Plata

Argentina

\title{
Estudio histórico y recreación virtual 3D del Panteón de los Ciudadanos Meritorios -Cementerio de la Recoleta- de Carlo Zucchi
}

Andruchow, Marcela*; Morita, Mercedes**; Delucchi, Amalia

Estudio histórico y recreación virtual 3D del Panteón de los Ciudadanos Meritorios -Cementerio de la Recoletade Carlo Zucchi

Estudios del Hábitat, vol. 18, núm. 1, 2020

Universidad Nacional de La Plata, Argentina

Atribución no comercial compartir igual (CC BY-NC-SA) 4.0 
Artículos

\section{Estudio histórico y recreación virtual 3D del Panteón de los Ciudadanos Meritorios - Cementerio de la Recoleta- de Carlo Zucchi}

3D Virtual Recreation of the Pantheon of the Meritorious Citizens of Carlo Zucchi

Marcela* Andruchow

Instituto de Historia del Arte Argentino y Americano.

Facultad de Bellas Artes. Universidad Nacional de La

Plata, Argentina

marcela_andruchow@yahoo.com.ar

Mercedes ${ }^{* *}$ Morita

Laboratorio de Ablación Láser, Fotofísica e Imágenes 3D.

Centro de Investigaciones Opticas (CONICET-CIC-

UNLP), Argentina

mercedesm@ciop.unlp.edu.ar

Amalia Delucchi

Facultad de Bellas Artes, Universidad Nacional de La

Plata, Argentina

amadelucchi@gmail.com

Recepción: 16 Diciembre 2019

Aprobación: 11 Mayo 2020

Publicación: 30 Junio 2020

Recepción: 16 Diciembre 2019

Aprobación: 11 Mayo 2020

Publicación: 30 Junio 2020

\section{Resumen:}

Este trabajo presenta los resultados de la propuesta de visualización digital 3D de una hipótesis de trabajo en el marco de los avances de investigación de la tesis de maestría de una de las autoras. Se enfoca en la combinación de indagación histórica en arquitectura y arte y la utilización de técnicas de digitalización 3D (modelado y registro). Se aboca al estudio de un conjunto de monumentos funerarios del Cementerio de la Recoleta (Buenos Aires, Argentina) denominado Panteón de los Ciudadanos Meritorios, erigidos entre 1832 y 1834, existentes en la actualidad y la reconstrucción 3D del proyecto arquitectónico del Panteón a los Hombres Ilustres de la Patria. Ambos elaborados por o con la intervención de Carlo Zucchi, arquitecto-ingeniero de la Provincia de Buenos Aires en esa época. Los monumentos estudiados son los dedicados a: Cornelio Saavedra (1831); Gregorio Funes (1831); Gregorio Perdriel (1832); Marcos Balcarce (1832); Antonio Sáenz (1833) y Juan Izquierdo (fallecido en 1834).

Palabras Clave: Monumento funerario, Historia, Digitalización 3D, Fotogrametría, Modelado 3D.

\section{Aвstract:}

This work presents the 3D digital visualization of a working hypothesis within the framework of the research advances of the master's thesis of one of the authors. It focuses on the combination of historical research in architecture and art and the use of 3D digitization techniques (3D modeling and 3D recording). The study of a set of funerary monuments of the Recoleta Cemetery (Buenos Aires, Argentina) called The Pantheon of Meritorious Citizens, erected between 1832 and 1834, existing today and the $3 \mathrm{D}$ reconstruction of the project of the Pantheon to the Illustrious Men of the Fatherland. Both elaborated by or with the intervention of Carlo Zucchi, Architect-Engineer of the Province of Buenos Aires at that time. The monuments studied are those dedicated to: Cornelius Saavedra (1831); Gregorio Funes (1831); Gregorio Perdriel (1832); Marcos Balcarse (1832); Antonio Sáenz (1833) and Juan Izquierdo (died 1834).

KEYWORDS: Funerary monuments, History, 3D digitalization, Photogrammetry, 3D modeling. 


\section{INTRODUCCIÓN}

Entre las aplicaciones de la digitalización 3D en bienes culturales, además del registro de la geometría y de los deterioros para fines de conservación, se encuentran aquellas que puedan colaborar en el estudio histórico de bienes artísticos y o arquitectónicos, a partir de la observación y análisis de modelos virtuales 3D. No sólo las técnicas de digitalización basadas en realidad capturada (captured reality) impactan en nuevas formas de visualización del patrimonio, sino también las técnicas tradicionales de modelado 3D. Cabe señalar la diferencia entre los términos registro 3D y modelado 3D. En este trabajo, el término modelado, lo usaremos para referirnos sólo a los procesos que implican el diseño o la creación de mallas a partir de otras ya estandarizadas que brindan los software más populares. Si quisiéramos modelar en 3D un objeto conocido, esto implica que para modelarlo debemos contar con alguna información sobre el objeto: las medidas reales, fotografías o planos con datos específicos, por ejemplo. En cambio, cuando nos referimos al registro, esto implica alguna técnica de adquisición de imágenes $3 \mathrm{D}$, es decir, métodos de realidad capturada, mediante escáneres láser o con fotogrametría digital, por ejemplo. El registro 3D permite obtener un modelo virtual pero con la diferencia de que se registra la apariencia, textura, color y proporciones reales del objeto, con una alta exactitud y resolución (Remondino, 2011; Remondino, Spera, Nocerino, Menna \& Nex, 2014; Roncella, Re \& Forlani, 2011; Morita \& Bilmes, 2018a; Schönberger, 2018; Bianco, Ciocca \& Garelli, 2018).

En este trabajo, se combinan ambos métodos: modelado y registro. El registro se aboca al estudio histórico y digitalización 3D de un grupo de monumentos erigidos en un lote del Cementerio de la Recoleta (Buenos Aires, Argentina) denominado Panteón de los Ciudadanos Meritorios y el modelado para la reconstrucción del proyecto de edificio para un Panteón dedicado a los Hombres Ilustres de la República en base a los dibujos de Carlo Zucchi, su autor. La combinación de métodos surge de la condición física de los objetos a estudiar: los monumentos existen actualmente, en cambio el edificio quedó solo en proyecto. Mediante esta combinación de métodos de reconstrucción $3 \mathrm{D}$ y de investigación histórica de los monumentos se pretende contrastar nuestra hipótesis de trabajo.

\section{Estudio históRICo}

\subsection{El cementerio de La Recoleta y los ciudadanos meritorios}

La costumbre de enterrar a los muertos ad santos ya sea en el interior de las iglesias o en cementerios construidos en su entorno inmediato tiene larga data (Ariès, 2000, p.23). En las colonias españolas esa costumbre se mantuvo largo tiempo hasta que hacia fines del siglo XVIII y con argumentos sanitaristas se comienza a ordenar desistir de esa práctica. En el caso del territorio argentino a principios del siglo XIX se reitera la prohibición e incluso se ordena en Buenos Aires en 1813, la construcción de un Panteón Público[1]. Pero estas disposiciones no se cumplen.

Es solo en el año 1822 en que por disposición del Gobernador Martín Rodríguez y su Ministro Bernardino Rivadavia se decreta el establecimiento de una necrópolis extramuros de la ciudad de Buenos Aires[2], constituyéndose el primer cementerio público de católicos. En el artículo $4^{\circ}$ del decreto del $1^{\circ}$ de julio de 1822, se estipula que "Queda destinado a Cementerio público el edificio prenominado [de la Recoleta]"[3]. Para que se cumpla con este punto se determina por el decreto del 8 de julio de 1822 que el camposanto de la Recoleta se denominará Cementerio del Norte, estando a cargo de un Capellán que también será su Administrador. El plano del predio se le solicita al entonces director del Departamento de Ingenieros Arquitectos de la provincia de Buenos Aires, Ing. Próspero Catelin, siendo la policía la encargada de controlar toda la actividad del cementerio, el cual se inaugura el domingo 17 de noviembre de 1822.

La instauración de la necrópolis formará parte de la gradual reforma de la estructura urbana que la elite gobernante formula en esta etapa. La cual consiste básicamente, en una zonificación de la ciudad acompañada de medidas regulatorias que reconocen una progresiva especialización urbana (Aliata, 2009, p.67). 
La preocupación por honrar a ciudadanos con mérito público está presente en los inicios del emplazamiento del cementerio, ya que en el decreto del 3 de septiembre de 1823 donde se estipula la tarifa de los lotes según su ubicación, el gobierno retiene para sí “....algunas sepulturas para asignarlas oficialmente a aquellas personas que se distingan por sus méritos contraídos en cualquier ramo del servicio público...”[4], de este modo se reserva un espacio de lotes para sepulturas destinado al panteón de los ciudadanos meritorios, a la derecha de la calle principal de entrada al cementerio, al que se suman otros lotes dispersos por la zona central del predio. La figura 1 muestra un mapa del camposanto.

Estos homenajes a los "hombres meritorios" encuentra su explicación a partir de que las circunstancias políticas que se desarrollan en ambas orillas del Río de La Plata -desde las invasiones inglesas en adelantecimentarán una dedicación especial dada a las glorias militares y en particular a los honores póstumos a los héroes de la reconquista y entrada ya la época independiente a los héroes militares de la independencia. Ese reconocimiento se verá traducido en relevantes celebraciones fúnebres, con rituales conmemorativos que recuerdan las exequias reales durante la colonia y equipamientos de arquitectura y arte efímeros de admirable inversión material y artística, a los que se agregaran los monumentos fúnebres emplazados en el cementerio público a partir de fines de la década de 1820.

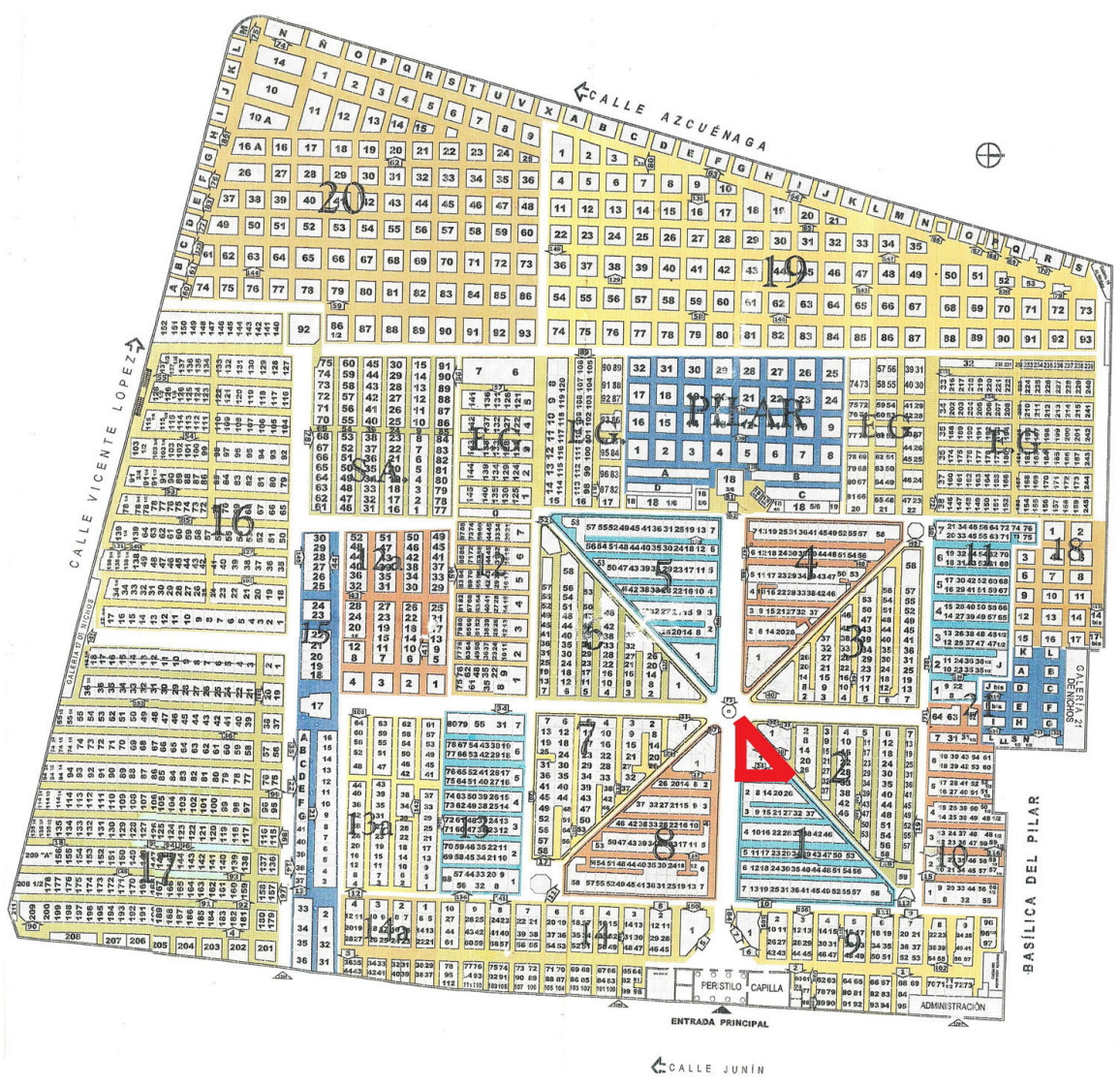

FIGURA 1

PLANO DEL CEMENTERIO DE LA RECOLETA. EL TRIÁNGULO ROJO SEÑALA LA UBICACIÓN DE LOS MONUMENTOS. FUENTE:ELABORACIÓN PROPIA

Si bien los homenajes a los hombres ilustres persistirán en lo sustancial, hacia finales de esa década y principios de la siguiente, se acentuará el culto a los primeros muertos de la Revolución de Mayo evidenciando cómo la provincia de Buenos Aires (durante el 1er Gobierno de Juan Manuel de Rosas) comienza a pensarse como una "comunidad imaginada", en la cual hay elementos comunes que deben resaltarse, y si bien no hay una historia patria todavía y menos aún una idea de nación, la memoria de los próceres fallecidos, el recuerdo 
de los sucesos de Mayo, generan, poco a poco, un imaginario que necesita de una arquitectura representativa que construya monumentos (Aliata, 2009, p. 76). Materializando en una arquitectura conmemorativa otra sepulcral proyectada sólo como efímera, que fue de las celebraciones fúnebres de las décadas anteriores.

Entre los honores que recibirán los ciudadanos con mérito por sus relevantes servicios a la sociedad se cuentan los establecidos por el decreto del 3 de junio de 1824 en cuanto a los respetos que el Cuerpo de la Honorable Junta de Representantes de la provincia debe ofrecer en caso de la muerte de un Honorable Diputado miembro de ese cuerpo[5]. Y los que emanan del decreto de la formación de una colección de libros autógrafa en los depósitos públicos: "Entre los manuscritos de la biblioteca pública se formará una colección autógrafa de las letras de todos los ciudadanos que hayan rendido y rindan servicios distinguidos a la patria"[6].

Los honores rendidos a estos ciudadanos van a incluir la dedicación de monumentos a su persona a erigirse en sus respectivas tumbas del Cementerio del Norte. Los 6 monumentos que se consideran en este trabajo (Figura 2 y Figura 3) fueron erigidos en el período de entre 1832 y 1834, cuando el arquitecto Carlos Zucchi era el Ingeniero Arquitecto de la Provincia de Buenos Aires.

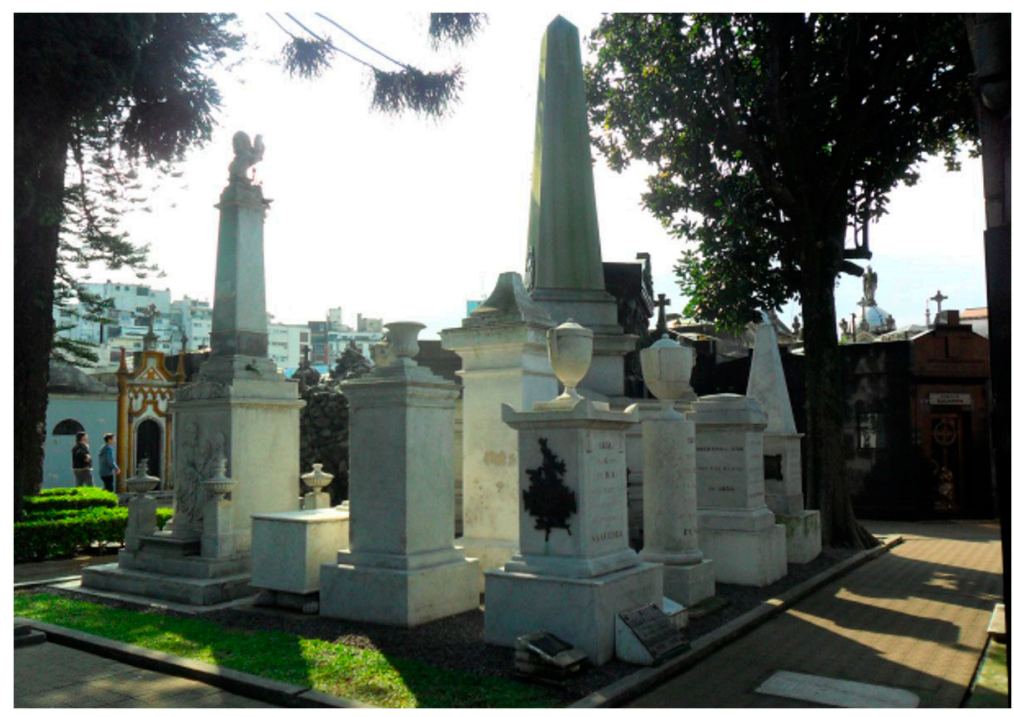

FIGURA 2

PANTEÓN DE LOS CIUDADANOS MERITORIOS. VISTA ACTUAL. FUENTE: ELABORACIÓN PROPIA

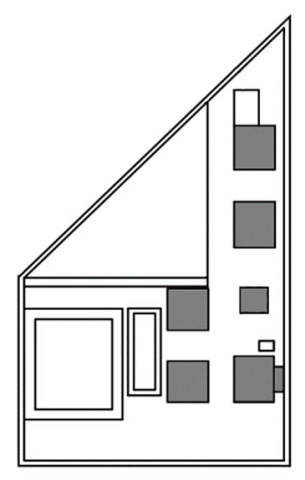

FIGURA 3

ESQUEMA DE PLANTA DEL PANTEÓN DE LOS CIUDADANOS MERITORIOS. FUENTE: CORTESÍA DE DI. WALTER CHILON

\subsection{La arquitectura de Carlo Zucchi y el Panteón}


Zucchi llega a Buenos Aires en 1827 y a partir de 1828 integra el cuerpo técnico que en conjunción con la elite gobernante practicará (en la medida que las circunstancias lo medien) la materialización edilicia de instituciones de la creciente especialización social que se va dando en Buenos Aires. Zucchi realiza "Monumentos, arquitecturas efímeras para fiestas públicas, edificios estatales y privados [que] se articulan dentro de la estética neoclásica como un sistema de signos que representan la cambiante realidad política" (Aliata, 2009, p. 67). Entre los encargos oficiales vinculados con el Cementerio del Norte, a Zucchi se le encomienda en octubre de 1829 , el proyecto y construcción de un monumento fúnebre para guardar los restos del gobernador Dorrego[7]; en 1831 proyecta una ampliación de la necrópolis en los predios del antiguo Jardín de Aclimatación lindero; en 1832 presenta una serie de diseños para sepulturas para tumbas de ciudadanos ilustres; y en los años que van de 1832 a 1834 interviene en el diseño y/o la dirección del emplazamiento de los monumentos fúnebres en honor a Cornelio Saavedra; Gregorio Funes; Gregorio Perdriel; Antonio Sáenz; Marcos Balcarce[8] y probablemente el de Juan Izquierdo[9]. A su vez, durante el año 1831, quizás el más prolífico en cuanto a su actividad arquitectónica en Buenos Aires, Zucchi proyecta una serie de "artefactos destinados a representar las glorias de la joven república y a honrar el heroísmo de sus próceres" (Aliata, 2009, p. 75). Estos trabajos no fueron encargos oficiales, por lo que se puede suponer que fueron iniciativas propias. De todos modos, oficiales o privadas estas iniciativas se vinculan con la tendencia del primer gobierno de Rosas de otorgar importancia y elaborar una efemérides patria y a la construcción de la imagen del nuevo gobierno federal como conciliador y superador de la etapa de anarquía anterior (Aliata, 2009, p. 75).

De entre esos artefactos nos interesa específicamente el de un panteón dedicado a los hombres ilustres de la República Argentina, ya que nuestra hipótesis, que retomamos de las afirmaciones y sugerencias de Fernando Aliata, lo supone como un edificio que albergaría en un futuro, los monumentos dedicados a los hombres ilustres de la república, reemplazando el sector del "Panteón de los Ciudadanos Meritorios", creado previamente en el área central de la necrópolis (Aliata, 2009, p. 75). "La idea de Carlo [Zucchi] es que el nuevo edificio debe englobar a las pequeñas sepulturas en un espacio mayor” (Aliata, 2009, p. 76) El diseño del mausoleo tiene un importante grado de elaboración, ya que lo componen siete láminas que detallan el exterior e interior del panteón. En la lámina de la perspectiva (Figura 4, izquierda) se aprecia la ubicación centralizada del edificio en un entorno descampado en el que se observan caminos rectilíneos trazados de modo regular que delimitan parcelas, vallado por un muro perimetral no muy alto, con una verja a modo de ingreso y la presencia de cipreses, que semejan el entorno descampado del cementerio para esos años y permiten suponer esa ubicación (Renard, 2009, p.246).

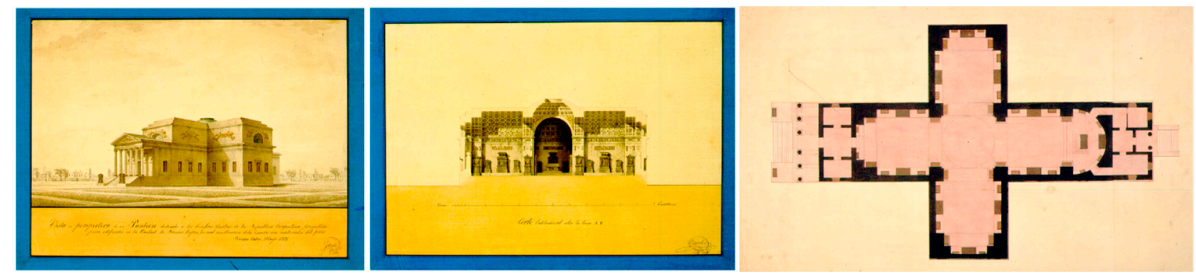

FIGURA 4

DIBUJOS DE ZUCCHI. IZQUIERDA: ASRE-AZ190 PROYECTO DE UN PANTEÓN DEDICADO A LOS

HOMBRES ILUSTRES DE LA REPÚBLICA ARGENTINA, A ERIGIRSE EN LA CIUDAD DE BUENOS AIRES.

VISTA EN PERSPECTIVA. BUENOS AIRES, MAYO 1831.415X580. CENTRO: ASRE-AZ192 IBÍDEM CORTE

TRANSVERSAL. 415X580. DERECHA: ASRE-AZ828 PLANTA [DE EDIFICIO MONUMENTAL] 572X363.

FUENTE: ARCHIVIO DI STATO DI REGGIO EMILIA. INVENTARI E CATALOGHI.

BADINI, GINO. 1996. "LA MEMORIA DEL FUTURO. CARLO ZUCCHI. INGENIERO

ARQUITECTO." CATÁLOGO MUESTRA MNBA 3-30 DE ABRIL DE 1996, BUENOS AIRES

El proyecto recupera la conocida tradición para este tipo de monumento, "la rotonda que evoca el martyrium recrea el consabido ejemplo del panteón de Agripa, combinado con la cruz griega de Santa 
Genoveva, convertida en panteón de Francia durante la Revolución y motivo de tantos ejercicios académicos que Zucchi debía conocer" (Aliata, 2009, p. 76). La construcción está asentada sobre un podio; el crucero está cubierto por una cúpula semiesférica. Posee un pórtico hexástilo de orden jónico rematado por un tímpano con relieves. Al pórtico se accede por una escalinata cuyos parapetos poseen un monumento funerario con relieves. El muro exterior está dividido en dos registros por un entablamento perimetral. En la parte inferior se ven treinta nichos con estatuas. El registro superior presenta alineados con los nichos, dos figuras aladas sosteniendo una cartela, salvo en la fachada principal y los extremos del transepto que aparece una ventana de arco de medio punto. El ático se presenta escalonado. Posee una única puerta adintelada (i) de ingreso en el centro del muro interior del pórtico. La fachada posterior correspondiente a las habitaciones del conservador presenta una angosta escalinata que da acceso a un pórtico con dos columnas jónicas. En el interior (Figura 4, centro y derecha) se observan sepulcros con relieves que se distribuyen de a tres por cada sector de muro, siendo el central más elevado y también hay sepulcros en las caras de los pilares donde apoyan los arcos. Por encima de los sepulcros hay relieves o inscripciones. Se observa un friso con relieves en el arranque de las bóvedas y los arcos. La cúpula y el ábside muestra un casetonado rectangular, en tanto las bóvedas uno hexagonal. El ábside que se alcanza subiendo dos escalones, presenta un sepulcro central con dos a sus lados; y en su centro, un altar en una plataforma con tres escalones. (Renard, 2009, p. 246)

El panteón aparece como el remate de una sucesión de proyectos conmemorativos y probablemente esté relacionado con un informe sobre el Cementerio del Norte que Zucchi había elaborado en 1830. Este diseño se presenta como bien ambicioso, ya que sus dimensiones resultan inéditas para este tipo de edificios en la ciudad de Buenos Aires de esa época, más si se lo ubicaba extramuros.

\subsection{Los Monumentos a los ciudadanos meritorios}

El 29 de marzo de 1829 fallece en Buenos Aires Cornelio de Saavedra, militar y destacado protagonista de la Revolución de Mayo y los sucesos políticos posteriores. La entrega de los honores póstumos a su dignidad será ofrecida unos meses más tarde, una vez restablecida la estabilidad en la provincia después del convulsionado año 1829. Las exequias se realizan finalmente el 22 de enero de 1830, tal como se relata en el periódico,

“Ayer se han celebrado en la Merced las exequias (...) por la alma del Sr. brigadier general D. Cornelio de Saavedra, con la pompa y solemnidad que anunciamos en nuestro numero anterior" [10].

El gobierno, para cumplir con este sagrado deber acuerda que en el Cementerio del Norte se levantará por cuenta del Gobierno, un monumento en el que se depositarán los restos del "Brigadier General Don Cornelio de Saavedra. [y] Se archivará en la Biblioteca Pública un manuscrito autógrafo del mismo Brigadier General. (Ministerio de Guerra, 1908, p. 56)[11].

El proyecto de colocación[12] del monumento será realizado por el Ingeniero Arquitecto de Provincia, el ingeniero Carlo Zucchi. En el presupuesto de albañilería que éste presenta a la autoridad el 26 de abril de 1831 se detallan las características del mismo. Será un monumento de mármol, grabado con una inscripción en letras de oro, colocado sobre los cimientos y la bóveda con revoque de argamasa donde descansaran los restos del brigadier[13].

En el mismo presupuesto, se incluye otro monumento que será destinado a honrar al difunto Deán Gregorio Funes, eclesiástico y político; hombre de letras y figura relevante de la Revolución de Mayo. El monumento en cuestión es semejante en gastos al dedicado a D. Cornelio de Saavedra, ya que el presupuesto que se presenta es por los dos monolitos a erigirse en conjunto, cuyo costo total es de 1428,- pesos.[14]

Entre los ciudadanos civiles que recibirán reconocimiento del Estado provincial se constata la figura del sacerdote Antonio Saenz. Este patricio había sido firmante del Acta de la Independencia de 1816 y primer Rector de la Universidad de Buenos Aires entre otros destacados servicios dados al país. Fallece en Buenos Aires el 25 de julio de 1825. Dos días después es promulgado un decreto según el cual

El Gobno (...) decreta. $1^{\circ}$ En el Cementerio del Norte, se destinará al Dr Dn Anto Saenz una de las sepulturas reservadas por el Gobno[15] (...) y se levantará en ella un monumento de mármol á la memoria de tan distinguido ciudadano. (...) [se aprobará] la inscripción que debe leerse en el expresado monumento. 
$3^{\circ} \mathrm{El}$ retrato del Dr Dn Antonio Saenz, (...) será colocado en la Sala de reuniones de dha corporación [la universidad]. $4^{\circ}$ Se depositará en la Biblioteca Pública uno de los escritos autógrafos del expresado Dr Dn Antonio Saenz[16]. $5^{\circ}$ Los gastos (...) serán cubiertos de los fondos discrecionales del Gobierno[17].

Esto no se cumple en su momento y, es sólo a partir del reclamo de la anciana madre del sacerdote doña Francisca Sarasa, que el gobierno de Juan Manuel de Rosas dará cuenta de lo anterior en 1832.

El proyecto de colocación del monumento es realizado por el ingeniero Carlo Zucchi, y en el presupuesto del plano adjunto se detalla que dicho monolito constará de "...Monumento de mármol conforme al plano adjto. Boveda y stilobato con cal y canto. Baranda de fierro. Inscripción (...) Total 1955, - pesos”[18]. El proyecto y presupuesto son aprobados y el ingeniero de provincia recibe en enero de 1832 el dinero para efectivizar la erección del monumento previsto.

En el caso del Coronel y Jefe de Policía Gregorio Perdriel, quien muere el 3 de marzo de 1832, el decreto de gobierno relativo a su fallecimiento destaca su vida pública en la carrera militar y en el desempeño de su importante y delicado destino y los servicios distinguidos que ha rendido a la causa de la restauración del orden y de las leyes. Como ciudadano digno de consideración del gobierno se acuerda

$1^{\circ}$ Será erigido un monumento a la memoria del Coronel Dn Gregorio Perdriel. (...)

$3^{\circ} \mathrm{El}$ monumento será colocado en el Cementerio del Norte en uno de los sepulcros destinados a los patriotas distinguidos. (...) $5^{\circ}$ Se depositará en la Biblioteca pública un manuscrito autógrafo del finado Dn Gregorio Perdriel.[19]

El general Marcos González Balcarce perteneció a la familia de guerreros de la independencia que llevaron ese apellido, fue militar y también magistrado en distintas épocas. Falleció el 4 de diciembre de 1832 y el gobierno, siguiendo el mismo sentido honorífico a los hombres que han dedicado sus servicios a la patria decreta que "En el Cementerio del Norte se destinará por cuenta del Gobno una sepultura en donde se depositarán los restos de Gral D. Marcos Balcarce”[20].

El General Juan Izquierdo fallece a la edad de 39 años el 27 de mayo de 1834 . Sus funerales se realizan el 7 de junio en la Iglesia de San Ignacio, según el aviso que publica su familia convocando a acompañarlos[21]. De este militar sabemos que acompañó a Dorrego en Navarro y que fue Comandante de campaña. Su monumento se encuentra junto al de Balcarce en el cementerio, donde a diferencia de otros no se consigna la fecha del decreto de erección.

\section{Materiales y MÉtodos}

\subsection{Fotogrametria de Structure from Motion}

Para el registro 3D de los monumentos, se utilizó el sistema de digitalización Mu3D, basado en fotogrametría digital con el método de Structure from Motion (SFM) (Morita \& Bilmes, 2018b; Micheletti, Chandler \& Lane, 2015). El procedimiento es sencillo: se toma una secuencia de fotos de un objeto, en diferentes posiciones y ángulos, y con el software que provee el sistema se obtiene una imagen tridimensional de alta resolución. Mu3D utiliza una interfaz gráfica de usuario amigable (GUI), creada por el Laboratorio de Ablación Láser, Fotofísica e Imágenes 3D del Centro de Investigaciones Ópticas (LALFI-CIOp), para el personal de los museos con el fin de facilitar la interacción con sistemas de software complejos involucrados en el proceso de reconstrucción 3D. Los software de SFM utilizados para este trabajo fueron: VisualSFM[22], CMP-MVS (Jancosek \& Pajdla, 2011), COLMAP[23] y OpenMVS[24]. Para la edición de los modelos obtenidos, la texturización y simplificación de las mallas poligonales se utilizaron los software de procesamiento de imágenes Blender[25] y MeshLab[26](Cignoni et al., 2008; Callieri, Cignoni, Corsini \& Scopigno, 2008). La adquisición de las imágenes se realizó con una cámara Nikon D5300, con una distancia focal entre 18-24 mm, dependiendo del monumento, pero siempre manteniendo fijo este valor en cada caso, un ISO de entre 100 y 400, un f/8-11 y una resolución de tamaño de 6000 x 4000 px. 
En un principio se pensó en trabajar un solo registro fotogramétrico de todo el sector de los monumentos, por lo que se tomaron varios conjuntos de fotos en diferentes momentos, de aproximadamente 380 fotos cada uno y en todos los ángulos posibles. Sin embargo, al ser un conjunto de monumentos muy grande y complejo, la cantidad de fotos y las ubicaciones de la cámara no fueron suficientes. También influyó la variación de luz ambiental durante las tomas y el hecho de no poder contar con escalera ni drones[27]. La figura 5 muestra la nube de puntos dispersa obtenida del registro fotogramétrico de todo el conjunto de monumentos. Una vez que se obtuvo la nube densa y luego la malla poligonal, los resultados no fueron satisfactorios en términos de exactitud y resolución. Frente a estos resultados parciales, se decidió hacer un registro individual de cada monumento. Por un lado para disponer de una iluminación pareja en el corto tiempo del registro, y, por el otro, para hacer tomas más cerca, aumentando el número de fotos y procesando por partes. La figura 6 ilustra el proceso completo de digitalización 3D con fotogrametría de SFM de uno de los monumentos.

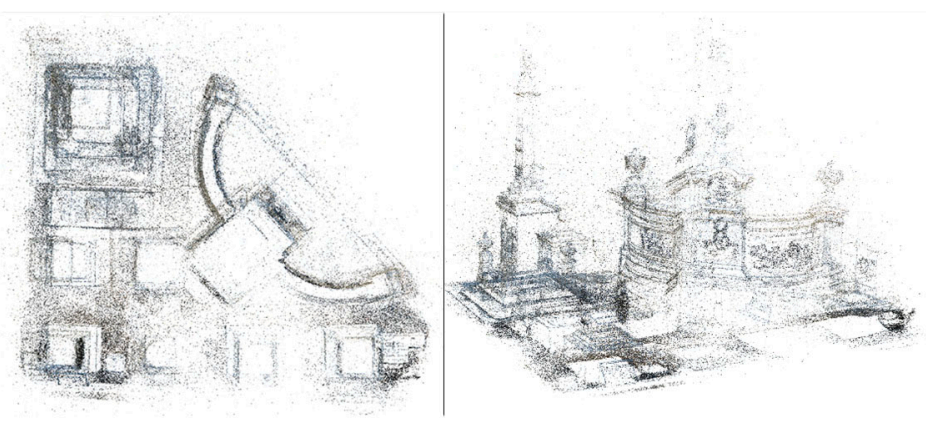

FIGURA 5

VISTAS DE LA NUBE DE PUNTOS DISPERSA OBTENIDA DEL PROCESO DE FOTOGRAMETRÍA DE SFM DE TODO EL CONJUNTO DE MONUMENTOS. IZQUIERDA: VISTA DESDE ARRIBA. DERECHA: VISTA EN ÁNGULO. FUENTE: ELABORACIÓN PROPIA.

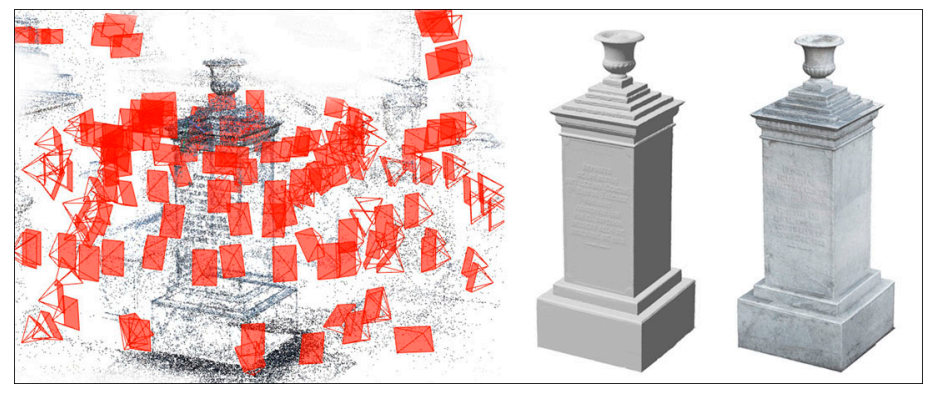

FIGURA 6

REPRESENTACIÓN DEL PROCESO COMPLETO DE DIGITALIZACIÓN 3D CON FOTOGRAMETRÍA DE SFM. IZQUIERDA: NUBE DE PUNTOS DISPERSA DEL MONUMENTO AL GENERAL MARCOS BALCARSE CON LA REPRESENTACIÓN DE LA UBICACIÓN Y ORIENTACIÓN DE LAS TOMAS FOTOGRÁFICAS. CENTRO: MALLA GENERADA CON EL FILTRO DE POISSON EN MESHLAB A PARTIR DE UNA NUBE DE PUNTOS MÁS DENSA. DERECHA: MALLA SIMPLIFICADA Y TEXTURIZADA. FUENTE: ELABORACIÓN PROPIA

\subsection{Modelado del Panteón a Partir de los dibujos de Zucchi}

Gracias a la disponibilidad de imágenes de la perspectiva, cortes y planta del edificio dedicado a Panteón del arquitecto Carlo Zucchi, ha sido posible su recreación virtual aproximada (Figura 7). Varias de las láminas contaban con una escala en varas castellanas[28], que permitió determinar las medidas aproximadas en metros del edificio no construido. Las dimensiones de edificio son aproximadamente: en su corte transversal 55 varas (45,65 metros); altura a la clave de la bóveda 19 varas (15,77 metros) y altura a la clave de la cúpula 
23 varas (10,09 metros). Por otra parte los monumentos dibujados en el interior de los cortes del edificio tienen aproximadamente 6 varas de alto (4,98 metros).

Para el modelado 3D del Panteón se utilizó SolidWorks, un software de diseño CAD 3D (diseño asistido por computadora) para modelar piezas y ensamblajes en 3D y planos en 2D. La metodología consistió en la generación de volúmenes a partir de extrusiones[29] de los dibujos de Zucchi. Primero, se construyeron los dos cortes del edificio (longitudinal y transversal) que dan forma a la cruz griega de la planta del edificio. Luego, se generó la cúpula central y los nichos rectangulares del perímetro murario; y se recortaron las aberturas superiores. Después, se realizaron las escaleras del frente y posterior del edificio, junto con la columnata del pórtico y el techo. Luego, se generaron sobrerrelieves en los suelos internos, para representar los bancos sobreelevados del interior del edificio donde en el dibujo de Zucchi se representa la posición de los monumentos a contener en el futuro edificio, según la idea del proyecto. Finalmente, se modelaron de forma muy esquemática los ornamentos arquitectónicos y escultóricos, tanto internos como externos.
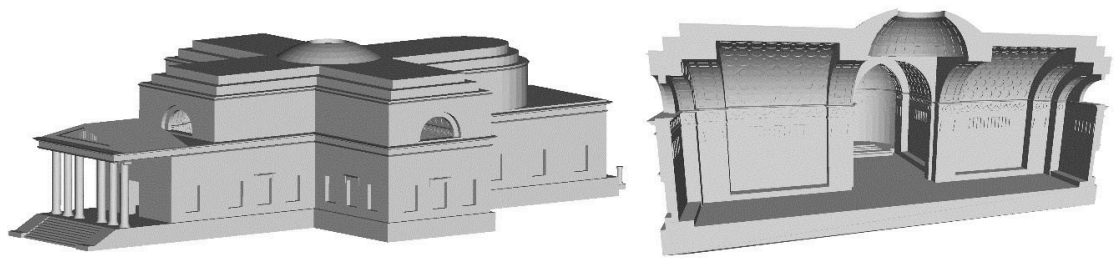

FIGURA 7

MODELADO DEL PANTEÓN. IZQUIERDA: EDIFICIO COMPLETO. DERECHA: CORTE TRANSVERSAL. FUENTE: ELABORACIÓN PROPIA

\subsection{TÉCNICAS DE TEXTURIZACIÓN Y RENDERIZADO}

Todos los monumentos y el edificio del Panteón fueron texturizados con el método de UV unwrapping[30]. En el caso de los monumentos, esta técnica de texturización permitió simplificar los modelos 3D (reduciendo la cantidad de polígonos de la malla) pero manteniendo la misma resolución en el aspecto visual de la textura. En algunos casos, fueron las fotografías ya alineadas (rasteres obtenido por el proceso de fotogrametría SFM) de cada monumento las que se utilizaron para generar los archivos de textura, mientras que, en otros casos, fueron los datos RGB de la nube de puntos densa (también obtenida por el proceso de fotogrametría SFM) (Corsini, Dellepiane, Ponchio \& Scopigno, 2009; Callieri, Cignoni, Dellepiane, Ranzuglia \& Scopigno, 2011).

La figura 8 muestra algunas de las imágenes utilizadas para texturizar el edificio del Panteón. Al no contar con archivos fotográficos, dado que el edificio no fue construido, ni datos de detalle de los revestimientos de pavimento y muros especificados por el autor del proyecto, los elementos para producir una textura (también por UV unwrapping) fueron dibujos y referencias de presupuestos de otros proyectos arquitectónicos de Zucchi, y fotografías de porciones de edificios construidos, a lo que se agregó el conocimiento que la arqueología urbana ofrece sobre los pavimentos utilizados en la época. Por ejemplo, una de las texturas para las baldosas del pavimento fue seleccionada a partir del detalle "de las cantidades y calidades de todas las clases de materiales que [se] necesitan para la refacción de la casa perteneciente al Señor D. Juan Martín de Pueyrreden, htando Calle de la Paz N ${ }^{\circ} 11$ "[31]. En dicho prospecto de una casa a refaccionar por el arquitecto Zucchi, se señala que ha de usarse baldosa francesa y del país. La imagen aplicada al piso modelado en $3 \mathrm{D}$ fue reproducida a partir de las publicadas de dichas baldosas en los resultados de excavación arqueológica del sitio de la estancia "La Elvira”, propiedad de la familia Ezcurra en el siglo XIX, partido de La Matanza (Ávido, 2015). Se eligió utilizar la imagen de una baldosa francesa, llamada coloquialmente así por su procedencia[32]. Este tipo de material de construcción hace su aparición en la ciudad de Buenos Aires en las últimas décadas del siglo XVIII. 
Las viejas casas coloniales comenzaron a transformarse, produciéndose la incorporación de nuevos materiales y la inclusión de otros tipos de solados como madera, piedra y baldosas, además de los consabidos enladrillados (López Coda, 1994) (o pisos de tierra apisonada más rústicos). Las baldosas mejoraron la higiene, siendo adoptadas, especialmente las de cerámica por su bajo costo respecto de las de mármol. La importación de baldosas francesas se inició en este período, aumentando e imponiéndose[33] durante el siglo XIX. Se han diferenciado dos tipos de baldosa francesa que provienen de los puertos de Francia que más se comercializaron en el Río de La Plata: las de Le Havre y las de Marsella. En este caso, las imágenes corresponden a baldosas cerámicas de Le Havre. Son reconocibles por su color superficial anaranjado salmón, por su textura porosa, áspera al tacto y con aristas levemente redondeadas. Medían aproximadamente 20,5 por $21 \mathrm{~cm}$ de lado, es decir, no llegaban a ser cuadradas. Para la texturización se partió de las excavadas en la Estancia La Elvira, que son baldosas de Marsella y se adaptaron los tonos y formas a las características propias de las de Le Havre, dado que para la fecha del diseño del Panteón, las baldosas que llegaban de puertos franceses al país provenían de Le Havre (López Coda, 1994). En cuanto a la textura de los muros, también se recurrió, en este caso al prospecto de Zucchi para la refacción de la casa de J.M. de Pueyrredón, donde presupuesta revoques "con cal a plan" [34] para varios sectores de la casa.

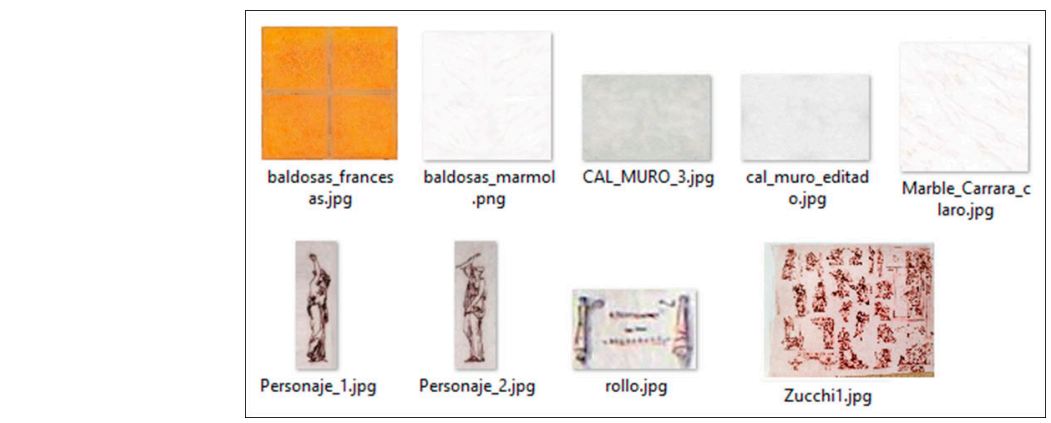

FIGURA 8

ARCHIVOS DE IMAGEN UTILIZADOS PARA TEXTURIZAR EL MODELO 3D DEL PANTEÓN.

FUENTE: ELABORACIÓN PROPIA

La otra textura de baldosas elegida fue de mármol. La variante se propone considerando la envergadura del proyecto de Zucchi para el edificio del Panteón, posiblemente pensado como un edificio con una lujosa inversión en materiales. En este caso, la textura de mármol fue utilizada tanto para el pavimento como para el revestimiento de los muros.

La textura para simular los personajes alegóricos de los frisos de las paredes fue obtenida de una lámina[35] de alegorías calcadas por Zucchi de otras fuentes (Fig. 8, Personaje_1, Personaje_2). La imagen de la cartela (Figura 8, Rollo) fue copiada de las decoraciones de los muros internos que se aprecian en los dibujos de los cortes del mausoleo.

\section{Resultados}

Una vez que se terminó de realizar el modelado y la texturización del edificio, se colocaron sobre él los modelos 3D de los seis monumentos del Cementerio de la Recoleta. Se respetó la escala real de todos los monumentos, lo que, visto en forma general, resultó en una notable diferencia proporcional respecto a los otros representados en los dibujos de Zucchi. La figura 9 muestra el corte y un detalle de una versión del edificio con piso de mármol, renderizada en Blender, con los monumentos ubicados en los bancos sobreelevados. Otra versión, con piso de baldosas francesas y muro caleado, muestra la figura 10. Para realizar los renderizados se diseñó un conjunto de iluminaciones cálidas y puntuales. 


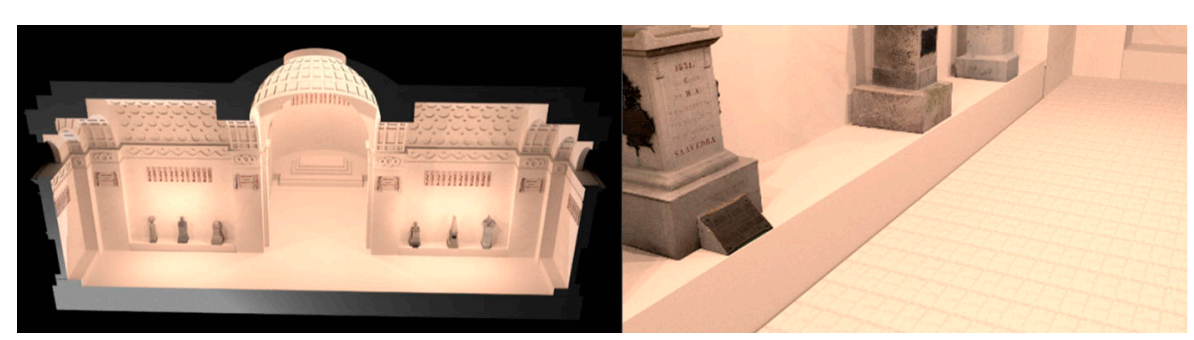

FIGURA 9

CORTE DE UNA VERSIÓN DEL EDIFICIO CON PISO DE MÁRMOL, RENDERIZADA EN BLENDER, CON

LOS MONUMENTOS UBICADOS EN LOS BANCOS SOBREELEVADOS. ABAJO, DETALLE DEL PISO. FUENTE: ELABORACIÓN PROPIA

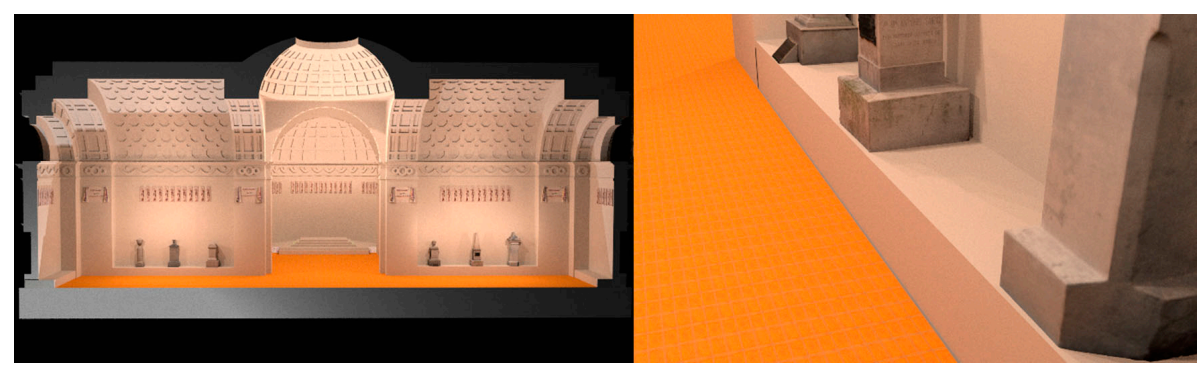

FIGURA 10

IMAGEN RENDERIZADA EN BLENDER, CON LA VERSIÓN DE PISO DE BALDOSAS FRANCESAS Y MURO CALEADO. FUENTE: ELABORACIÓN PROPIA

\section{Conclusiones}

A partir de la combinación entre la investigación histórica, el modelado del edificio del Panteón proyectado por Zucchi y el registro y reconstrucción 3D de los monumentos, pudimos visualizar la hipótesis de la cual partimos en el trabajo. Se hace claro en la constatación de las dimensiones del edificio proyectado y nunca realizado, con las medidas de los monumentos, que no coinciden en su envergadura. Los monumentos poseen medidas promedio que rondan entre 2,50 y los 3 metros de alto, en tanto el Panteón proyectado dimensiones de mucha más magnitud. Por esto podemos descartar que los monumentos efectivamente erigidos y que se conservan in situ en la actualidad, fueran los destinados a integrar el edificio en caso de que fuera construido. Como alternativas a esta constatación, podemos pensar en las persistentes y permanentes limitaciones de presupuesto que aquejaban al Estado provincial y que resultaron en la imposibilidad de dedicar monumentos con mayor gloria y magnitud en honor a los hombres meritorios de la provincia, y en la erección del proyectado Panteón. Pero otra alternativa puede suponerse de la operación de Zucchi como arquitecto proyectista y funcionario técnico del Estado provincial. La situación del arquitecto como miembro del cuerpo técnico no había estado a la altura de sus expectativas desde el comienzo de su actuación. La inestabilidad política, la carencia de recursos y el escaso desarrollo profesional del medio y de la apreciación de sus competencias por parte de los comitentes públicos o privados en el Río de La Plata de la primera mitad del siglo XIX, había ocasionado una intensa decepción en Zucchi[36]. Podemos pensar entonces que los ensayos de diseño que realiza el arquitecto están orientados a publicitar sus conocimientos y competencias como proyectista en vistas a un futuro retorno a Europa[37]. Esta acción publicista se verifica en la publicación en 1835 de un prospecto de la "Colección de los principales proyectos", realizados por Zucchi entre 1828 y 1835, donde constan listadas sus propuestas urbanas y arquitectónicas efectuadas y no. Dicho prospecto solicita suscriptores para la producción y edición de las láminas. Finalmente, no logra salir a la luz por falta de suscriptores, pero allí aparece el Panteón para los hombres ilustres como una de sus obras. 
Finalmente, la digitalización 3D realizada también tiene la posibilidad de utilizarse con fines de difusión al público, entretenimiento y educación. En este sentido, se creó una aplicación de realidad aumentada para las imágenes 3D de los seis monumentos digitalizados.

\section{Agradecimientos}

A DI Walter Chilon por su contribución en la realización del plano en Autocad de la parcela donde se encuentran los monumentos estudiados.

A Dr. Arq. Fernando Aliata por la sugerencia de la hipótesis que condujo esta investigación.

A Daniel Loaiza por sus aportes en los procesos de texturización y renderizado de los modelos 3D.

\section{RefEREnCias}

Aliata, F. (2009). Carlo Zucchi. Arquitectura. Decoraciones urbanas. Monumentos. Buenos Aires: ArT Digital.

Ariès, P. (2000). Historia de la muerte en Occidente. Barcelona: El Acantilado

Ávido, D. (octubre, 2015). Marcas comerciales de las baldosas cerámicas recuperadas en el sitio La Elvira (Virrey del Pino, Provincia de Buenos Aires). Póster presentado en VI Congreso Nacional de Arqueología Histórica. Recuperado de: https://zenodo.org/record/1412840\#.XbD355pKiaE

Badini, G. (1996). La memoria del futuro. Carlo Zucchi. Ingeniero arquitecto. Catálogo muestra Museo Nacional de Bellas Artes, 3-30 de abril de 1996, Buenos Aires

Bianco, S., Ciocca, G., Marelli, D. (2018). Evaluating the Performance of Structure from Motion Pipelines, J. Imaging 4 (8) [98]. doi:10.33.90/jimaging4080098

Callieri, M., Cignoni, P., Corsini, M., Scopigno, R. (2008). Masked Photo Blending: mapping dense photographic dataset on high-resolution 3D models. Computer and Graphics, 32 (4). [464-473]. doi: 10.1016/ j.cag.2008.05.004

Callieri, M., et. alt. (2011). Processing a complex architectural sampling with Meshlab: the case of Piazza della Signoria. International Archives of the Photogrammetry, Remote Sensing and Spatial Information Sciences, Volume XXXVIII-5/W 16, 2011ISPRS Trento 2011 Workshop, 2-4 March 2011, Trento, Italia.

Cignoni, P., et. alt. (2008). MeshLab: an open-source mesh processing tool. Proc. Eurographics Italian Chapter Conference. [129-136]. Recuperado de: doi: 10.2312/LocalChapterEvents/ItalChap/ ItalianChapConf2008/129-136 1

Corsini, M., et. alt. (2009). Image-to-Geometry Registration: A Mutual Information Method exploiting Illumination-related Geometric Properties. Computer Graphics Forum, 28 (7) 1755-1764. doi.org/10.1111/ j.1467-8659.2009.01552.x

Jancosek, M. y Pajdla, T. (2011). Multi-View Reconstruction Preserving Weakly-Supported Surfaces, Proc. IEEE Conference on Computer Vision and Pattern Recognition. doi:10.1109/CVPR.2011.599569

López Coda, P. (1994). Historia de los materiales de construcción. Las baldosas cerámicas en el Río de La Plata. Revista del IAA (Instituto de Arte Americano e Investigaciones Estéticas), No 50, agosto 1994. Buenos Aires. https:// www.arqueologíadigital. com/page/biblioteca-virtual

Micheletti, N., Chandler, J.H., Lane, S.N. (2015). Structure from Motion (SfM) Photogrammetry. Photogrammetric beritage, $2,1-12$

Ministerio de Guerra. (1908). Historia de los premios militares. República Argentina. Leyes, decretos demás resoluciones referentes a premios militares, recompensas, honores, distinciones, gratificaciones, etc. Buenos Aires: Talleres Gráficos, Arsenal Principal de Guerra

Morita, M., Bilmes, G.M. (2018) (a). Applications of low-cost 3D imaging techniques for the documentation of heritage objects. Óptica Pura y Aplicada, 51 (2) 50026: 1-11. doi.org/10.7149/OPA.51.2.50026 
Morita, M.M. y Bilmes G.M. (2018) (b).3D imaging system for the digitization of the Argentine museums collections. Revista Kermes - Restauro, conservazione e tutela del patrimonio culturale, 107. 45-49

Prado y Rojas, A. (1877). Leyes y decretos promulgados en la provincia de Buenos Aires desde 1810 hasta 1876. Buenos Aires: Imprenta Mercuri

Remondino, F. (2011). Heritage Recording and 3D Modeling with Photogrammetry and 3D Scanning, Remote Sensing, 3(6), [1104-1138]. Recuperado de: doi:10.3390/rs3061104

Remondino, F., Spera, M.G., Nocerino, E., Menna, F., Nex, F. (2014). State of the art in high density image matching. The Photogrammetric Record, 29 (146), [144-166]. Recuperado de: doi: 10.1111/phor.12063

Renard, M. (2009) Panteón dedicado a los hombres ilustres de la República Argentina. En Aliata, (ed.). (2009). Carlo Zucchi. Arquitectura. Decoraciones urbanas. Monumentos. Buenos Aires: Art Digital

Roncella, R., Re, C., Forlani, G. (2011). Performance evaluation of a structure and motion strategy in architecture and cultural heritage. Int. Arch. Photogramm. Remote Sensing Spat. Inf. Sci. 38 [285 292]. doi:10.5194/ isprsarchives-XXXVIII-5-W16-285-2011

Schávelzon, D. (1991). Arqueología histórica de Buenos Aires I. La cultura material porteña de los siglos XVIII y XIX. Buenos Aires: Corregidor

Schönberger, J.L. (2018). Robust Methods for Accurate and Efficient 3D Modeling from Unstructured Imagery, ETH Zürich

Terp, R. (2009) Tumbas en el Cementerio del Norte. En Aliata, F (ed.). (2009). Carlo Zucchi. Arquitectura. Decoraciones urbanas. Monumentos. Buenos Aires: ArT Digital

\section{Notas}

* Marcela Andruchow es Profesora de Historia de las Artes Visuales por la Universidad Nacional de La Plata y Museóloga por el ISFDyT 8. Es subdirectora del Instituto de Historia del Arte Argentino y Americano, FBA-UNLP. Realiza investigación en el área de Gestión, Conservación y Documentación de bienes culturales y artísticos. Es docente Titular de la Facultad de Bellas Artes e Investigadora Cat. II.

${ }^{* *}$ Mercedes Morita es Doctora en Artes por la Universidad Nacional de La Plata y Licenciada en Conservación y Restauración de Bienes Culturales por la Universidad Nacional de las Artes. Trabaja en el Laboratorio de Ablación Láser, Fotofísica e Imágenes 3D (LALFI) del Centro de Investigaciones Ópticas (CIOp) y se especializa en el registro de imágenes 3D para documentación de bienes artísticos y culturales.

*** Amalia Delucchi es Diseñadora Industrial por la Universidad Nacional de La Plata. Ayudante de las Cátedras Visión 2, Taller de Diseño Industrial 1B y Taller de Diseño Industrial 5B, FBA, UNLP.

[1] Decreto №342. "Prohibiendo las inhumaciones en los Templos y mandando formar cementerios". 10 de junio de 1813. (Prado y Rojas, 1877).

[2]Decreto No 528 "Cementerios públicos", 13 de diciembre de 1821 y decreto № 612 "Convento de la Recoleta", $1^{\circ}$ de julio de 1822. (Prado y Rojas, 1877).

[3]Decreto No 612 “Convento de la Recoleta”. 1 de julio de 1822. (Prado y Rojas, 1877).

[4]Decreto 705. “Sepulturas”. 3 de septiembre de 1823. (Prado y Rojas, 1877).

[5] La Honorable Junta de Representantes de la Provincia, penetrada de un justo sentimiento por la muerte del Honorable Diputado, ha venido a decretar y decreta lo siguiente: Art. $1^{\circ}$. Una comisión de este Cuerpo, compuesta de tres individuos, asistirá á nombre de la Sala, al entierro y funerales, del finado representante, haciendo el duelo con los parientes. $2^{\circ}$. Los individuos que compongan la Comisión llevarán en el brazo izquierdo un velillo negro. $3^{\circ}$. El Presidente de la Sala pasará á la familia del finado una carta de pésame en que á nombre de esta corporación se exprese el sentimiento que lo anima por tan melancólico acontecimiento. $4^{\circ}$ Lo dispuesto en este decreto se tendrá por una disposición general para casos de igual naturaleza..." Decreto 748 . "Honores fúnebres en la muerte de un miembro de la Honorable Legislatura”. 3 de junio de 1824. En: Prado y Rojas, Aurelio. 1877. Leyes y decretos promulgados en la provincia de Buenos Aires desde 1810 hasta 1876. Buenos Aires. Imprenta Mercurio. 
[6]Decreto 482. "Colección autógrafa”. 6 de octubre de 1821. (Prado y Rojas, 1877).

[7] Este encargo incluía además el proyecto del catafalco para honrar al depuesto gobernador.(Aliata, 2009, p. 66)

8]Es interesante notar que la grafía de este apellido se halla escrita con 's' en la leyenda de la lápida de mármol de su monumento respectivo en el Panteón.

[9] Respecto del monumento a Marcos Balcarce, si bien se conoce el decreto de dedicación de honores póstumos que incluye la erección de un monumento en el Cementerio del Norte, no se ha hallado material que confirme el diseño o intervención presumida de Zucchi. En cuanto al monumento en honor a Juan Izquierdo al momento no se constata la fecha de la erección y las fuentes son escasas como para poder confirmar la intervención de Zucchi, a pesar de constatar en el diseño la estética neoclásica propia de los diseños del arquitecto.

En este sentido Terp (2009) afirma que "en su Colección de los Principales Proyectos, Zucchi declara haber hecho en total 28 proyectos para monumentos sepulcrales (...). De todos modos, las fuentes gráficas de estos trabajos son escasas o inexistentes. (...), esta incompleta colección de fuentes permite identificar numerosos trabajos suyos (...) ejemplos que actualmente se encuentran en el Panteón de los Ciudadanos Meritorios del Cementerio de La Recoleta. Sin embargo, no podemos saber hasta qué punto participó en el proceso creativo de su diseño y materialización” (Terp, 2009, p. 241).

[10]Diario Universal. No 84, sábado 23 de enero de 1830.

[11]]Decreto "Honores póstumos al General don Cornelio de Saavedra". 16 de diciembre de 1829. (Ministerio de Guerra (1908), p. 56). La orden de archivar un manuscrito del difunto alude al decreto ya mencionado sobre la colección autógrafa.

[12]En este caso y el del Deán Funes no es clara la intervención de Zucchi en el diseño de los túmulos, ya que, si bien en el archivo Carlo Zucchi se hallan bocetos de este tipo de obra con claras similitudes a los monumentos erigidos, se constata que los túmulos ya preexistían en dependencias del gobierno. Ver AGN, Sala X, 44-6-18 y Terp, R. (2009) p. 241

[13]Archivo General de La Nación (AGN), Sala X, 36-3-10. 26 de abril de 1831, foja 87.

[14]El Deán Gregorio Funes fue enterrado en el Cementerio de la Recoleta, pero luego sus restos fueron trasladados a una tumba sita en la catedral de Córdoba.

15]Se refiere al lote de sepulturas reservado para uso oficial por el Decreto 705. "Sepulturas". 3 de septiembre de 1823. (Prado y Rojas, 1877).

[16]Aquí se alude al Decreto 482. “Colección autógrafa”. 6 de octubre de 1821. (Prado y Rojas

[17]AGN, Sala X, 36-4-5. 1832-1833. Policía. Cementerio. Gastos extraordinarios.

[18]AGN, Sala X, 36-4-5. 1832-1833. Policía. Cementerio. Gastos extraordinarios

[19]AGN, Sala X, 33-1-6, 1832. Policía, Libro 56.

[20]AGN, Sala X, 33-1-6, 117. Gaceta Mercantil, 6 de diciembre de 1832.

[21] Diario El Monitor, 5 de junio de 1834.

[22] VisualSFM: http://ccwu.me/vsfm/

[23] COLMAP: https://colmap.github.io

[24] OpenMVS: https://openmvg.readthedocs.io/en/latest/software/MVS/OpenMVS/

[25] Blender: https://www.blender.org

[26] MeshLab: http://www.meshlab.net

[27]La Dirección General de Cementerios de la Ciudad de Buenos Aires no permite el uso de drones dentro del cementerio. Y si bien inicialmente no contábamos con escalera, finalmente pudimos acceder a una, pero por la altura de algunos de los monumentos no se puedo completar el registro fotográfico.

[28] 1 vara castellana $=0,83$ metros 
[29] Técnica de modelado 3D donde un perfil en dos dimensiones o sección es prolongado a lo largo de un camino, de tal manera que se crea una continuidad de perfiles en tercera dimensión. El resultado puede ser una superficie, un sólido o una secuencia de secciones. Extruir crea una operación extruyendo un objeto 3D a partir de un croquis 2D.

[30] Esta técnica consiste en desplegar los polígonos de la malla para que coincidan con una imagen bidimensional (es decir, fotografías de los objetos).

[31] Zucchi, C. “Casa perteneciente al señor Juan Martín de (Puerjeden), Calle de la Paz n 11. Prospecto”. ASRE-AZ Carte porfesionali minute. Memorie 1. Archivio di Stato di Reggio Emilia. Inventari e cataloghi. (Badini, 1996).

[32] Siguiendo a Schávelzon (1991), "las baldosas en el sentido moderno son una tradición francesa, llegada durante el siglo pasado con la gran importación de materiales de construcción que inundó el país a partir de 1852.Los puertos las recibieron desde antes y de todas las ciudades europeas, aunque en general venían de Marsella y de Pas de Cales”. (p. 196).

[33] En contextos de excavación de esta época, lera mitad del siglo XIX, se detecta también la presencia de baldosas delgadas de fabricación artesanal, conocidas como baldosas "del país", cuya utilización fue sistemática junto a la de las importadas de Francia. (López Coda, 1994).

[34] Zucchi, C. “Casa perteneciente al señor Juan Martín de (Puerjeden), Calle de la Paz n 11. Prospecto”. ASRE-AZ Carte porfesionali minute. Memorie 1. Archivio di Stato di Reggio Emilia. Inventari e cataloghi. (Badini, 1996).

[35] Zucchi, C. "Prova di disegno", N 891. Archivio di Stato di Reggio Emilia. Inventari e cataloghi. (Badini, 1996).

[36] En una carta que Carlo Zucchi le escribe en 1831 a su amigo Victor Pedretti, artista, que vive en París, y quién le pide su opinión sobre el comercio de las bellas artes en el Río de La Plata, Zucchi responde que es muy delicado hacer alguna afirmación y continua: "Buenos Aires es una tierra muy joven para que en ella las bellas artes puedan tener vigor, por consecuencia también éstas están en la infancia, y para los artistas de cualquier origen no es un país que les pueda suministrar el modo de hacer no ya una brillante fortuna sino tan siquiera mediocre. Aquí se desconoce el grabado, no se tiene ninguna idea de pintar al fresco, a la tempera o a la cal. Ni siquiera se sabe lo que son los pintores históricos. La idea que se tiene de la litografía es menos que cero. La arquitectura, que no es solo la que tendrían que necesitar sino también la que les hace falta -y hablo de arquitectura simplemente civil, la que sirve para distribuir, apara hacer cómoda una vivienda-la descuidan de tal manera que prefieren un albañil a un arquitecto o un ingeniero". Carta a Monsieur m Victor Pedretti, artista. Cartas de Carlo Zucchi. Apéndices documentales. (Aliata, 2009, p.180).

[37] En este sentido relacionamos la referencia que hace Fernando Aliata respecto de otro proyecto de Zucchi: En 1831 el arquitecto presenta el proyecto de un hospital para ambos sexos en respuesta a un pedido del gobierno. En este proyecto Zucchi invierte 8 meses de trabajo, incorporando información actualizada de la tratadística de la época para esa tipología. El proyecto es de importancia considerable para el gobierno, que lo exhibe en las oficinas del fuerte. Tan novedoso es el diseño que Zucchi solicita permiso para presentar su obra en las principales academias europeas. Si bien el gobierno niega la solicitud, este proyecto por la absoluta renovación de las técnicas hospitalarias debía otorgar reconocimiento internacional al arquitecto. (Aliata, 2009, p. 77).

\section{BY-NC-SA}

